\title{
Persuasive Strategies of Saudi EFL Learners
} https://doi.org/10.33806/ijaes2000.22.1.15

\author{
Rehan Almegren \\ Princess Nourah bint Abdulrahman University, KSA
}

Received on 28.1.2021 Accepted on 3.10.2021 Published on 1.1.2022

\begin{abstract}
The aim of this study is to investigate the speech act of persuasion used by Saudis learning English as a foreign language (EFL). Moreover, I seek to explore the differences between genders in the use of these strategies. The participants are 50 males and 50 females at level 7 of their bachelor's degree in English. Data are collected using the Discourse Completion Test (DCT) method, which contains six scenarios similar to real-life situations. Data are analysed quantitatively using the Cross-Cultural Speech Act Realization Project nine-point rating scale, Statistical Package for the Social Sciences, and Chi-square. The results of the DCT reveal that Saudi EFL learners use more direct strategies in English, namely hedge performatives and performatives. In addition, males are shown to be more inclined to use direct persuasive strategies compared to females. This research will benefit language learners, teachers, and researchers, as it highlights linguistic aspects of the speech act of persuasion that should be considered when learning and teaching a foreign language. The implications of this study inspire future research into different aspects of speech acts.
\end{abstract}

Keywords: EFL, linguistics, persuasion, pragmatics, speech acts, Saudi

\section{Introduction}

Language is considered a basic instrument that enables communication. Individuals across societies use language in everyday interactions, as well as in different forms of speech acts that are part of the essence of different cultures. Not only are these speech acts performed, but their practice is vital, from a sociolinguistic perspective. Learning a foreign language ultimately involves learning another culture that differs from the learner's culture. Gass and Houck (1999) claim that it is immensely important that foreign language learners learn speech acts, as it will enable interactions with native speakers of that language. This requires a pragmatically aware learner.

Pragmatics is an important linguistic field. Koike (1996) defines it as the relatedness of language to contextualized use and communication. Speech acts are the main aspects of pragmatics (Pishghadam and Rasouli, 2011) and are verbal actions, as emphasized by Austin (1962). Speech act theory is concerned with how language is used and the functions it serves. Austin (1962) describes the language of speech as not necessarily descriptive of the world, but rather a performative of a variety of actions. When a speaker uses these speech acts, they are accomplishing something in terms of communication; for example, speech acts are used to greet, apologize, congratulate, or persuade. 
As pointed out by Searle (1969), the speech act of persuasion is considered a directive speech act. More specifically, it is the effort one exerts in attempting to change the point of view, feelings, intentions, and behaviour of others (Lakoff 1982). People encounter or use the speech act of persuasion nearly every day in many ways, either in spoken, visual, or written forms. Part of learning a language is learning how to persuade in the target language (English in this case). This study investigates the speech act of persuasion in male and female Saudi English learners. It aims to establish whether English as a foreign language (EFL) learners from Saudi exhibit significant differences in how they apply their persuasive strategies.

I also investigate the differences between male and female Saudi EFL learners in how persuasive strategies are applied. Investigating how speech acts are used among learners helps teachers improve the teaching of a foreign language and widens the learning perspective. Moreover, by learning not only the language, but also the culture that underlies the language, communication will be more accurate and effective. This implies that teachers should differentiate between linguistic forms or interactions in a foreign language and communicative competence.

Kasper and Rose (2002) point out that succeeding in learning the grammar of a target language does not necessarily mean that the learner will share the same level of pragmatic understanding as a native speaker of that language. To be pragmatically competent simply requires avoiding miscommunication problems. More effective communication occurs as a result of being pragmatically competent. Many studies have been conducted on the different speech acts of EFL learners, but few have focused on the strategies and gender differences of these speech acts. In this study, aspects of the speech act of persuasion focusing on Saudi EFL learners are investigated for the first time. Our study follows in the footsteps of Pishghadam et al.'s (2011) research on Iranian EFL learners' persuasive strategies.

\section{Literature review}

Pragmatics is defined as the ways in which language is used in the context of communication (Koike, 1996). Pragmatics also examines how language is used in certain specified ways. Yule (1996:3) points out that pragmatics involves four areas: speakers' meaning, expression of relative distance, contextual meaning, and implied meaning beyond what is said. The manner in which second language pragmatics is acquired remains an area that requires investigation, especially when pertaining to Saudi native Arabic speakers learning English.

Selinker (1972) refers to interlanguage as a language system of a learner that is considered inconsistent with that of the native speaker. Pragmatics, when linked with second language acquisition, has created a subfield referred to as interlanguage pragmatics. It is "the branch of second language research which studied how nonnative speakers understand and carry out linguistic actions in a target language, and how they acquire L2 pragmatic knowledge," as defined by Kasper (1992:203).

For language learners to be pragmatically competent, they must be able to appropriately use the target language in different socio-cultural contexts (Taguchi, 2009). Yule (1996) claims that contextual meaning, implied meaning, and the speaker are all aspects of pragmatics. Verschueren (1999) adds to Yule's definition 
and states that meaning is dynamic rather than static. This highlights the importance of this study, as it investigates language users of different interactive contexts. Faerch and Kasper (1983) state that there are two types of pragmatic competence: The first type is procedural knowledge, which "refers to the process of selecting and combining declarative knowledge from these categories" (Morkus, 2009). The second type is declarative knowledge, which has six different types: sociocultural, linguistic, context, discourse, and knowledge of the world. This suggests that pragmatic competence is linked to linguistics and socio-culture.

Wide interest in the field and essence of pragmatics caused Austin to publish his book How to Do Things with Words in 1962, in which he proposes speech act theory. Searle (1969) later developed that theory, and defined speech acts as the ability of an utterance to do things. Speech act theory refers to communication being the basis of the pragmatic theory of language. Searle (1969:16) states that "all linguistic communication involves linguistic acts." The speech act of persuasion is one of various kinds of speech acts, as pointed out by Austin (1962). According to him, there are differences between locutionary acts, perlocutionary acts, and illocutionary acts. He says that a speaker utters sentences with a particular meaning (locutionary act) and with a particular force (illocutionary act), in order to achieve a certain effect on the hearer (perlocutionary act) (Austin, 1962: 101).

Searle (1969) classifies illocutionary speech as assertive, directive, expressive, performative, and commissive. "Assertive" refers to how the speaker is committed to the proposition expressed; "directive" represents an action that the listener takes in response to the speaker; "expressive" is concerned with the speaker's psychological inner state; "performative" refers to verbs that describe actions that have been carried out by the utterers; and "commissive" represents acts that are speaker-centred.

The speech act of persuasion is considered to be a perlocutionary act andaccording to Searle (1969) - is directive. It directs the hearer to take action, and for the action to happen, the speaker needs the attention of the hearer. Utterances made by the speaker can appear in the class of illocutionary speech acts and can be classified as directive speech acts (Jibreen and Al-Janabi, 2018). Taufik (2014:192) discusses Jibreen et al.'s (2018) study and adds that "As a result, directives are classified as directives in the form of direct utterances and in the form of indirect utterances, i.e., other acts that are not directives, but they carry out the sense of directness." It is important to note that Brown and Levinson (1987) consider the speech act of persuasion as a threatening act according to their politeness theory.

The speech act of persuasion has been investigated from different angles in many languages by different speakers and learners of those languages. An interesting study was presented by Hardin (1999), who investigates how audiences were persuaded by speech acts employed in Spanish television advertisements. The study shows that persuasion was composed of more than one speech act. While there were no signs of the use of declaratives, assertives and directives were regularly used in those advertisements. Most directives used in the advertisements were orders, and they were used to make the audience conform to the advertiser's 
wishes. Suggestions, recommendations, and invitations were also provided. Advertisers ensured using commissives for confidence building between the receiver and the teller, and this was done through promising and guaranteeing. Complementing, praising, and flattering are also types of expressives used.

Alhudhaif (2005) investigates the contribution of editorials in both English and Arabic languages to the speech act of persuasion. This study explores the similarities and differences between Saudi and American cultures. The method of data collection was in the form of 26 editorials of different American newspapers and 26 editorials from different Saudi newspapers. The data were analysed using the speech act taxonomy coding system presented by Searle (1976). The results of that study revealed that commissives and declaratives did not contribute to directives, expressives, and representatives.

Chakorn (2006) presents a comparative study of the strategies of the speech act of persuasion. It was applied to native Thai speakers who spoke English and native English speakers, by analysing their letters of request. The data were analysed using quantitative and qualitative methods. This was done by contrasting texts linguistically and pragmatically. The method of analysis was the persuasive rhetorical Aristotelian concept. The results of that study revealed that native English speakers used stronger logos (reasoning as a way of persuasion). The results also indicated that there were differences in the persuasive strategies used by the two groups, which may have been due to their cultural backgrounds.

Another study presented by Hardin (2010) examines intermediate Spanish learners and the persuasive strategies they produced in different situations. The participants responded orally to the situations they were given. Their responses were compared to those of native speakers, and the results showed that being in the intermediate level signified that there were signs of them starting to understand persuasive strategy methods. It also showed that these responses were not pragmatically accurate. Hardin emphasizes that there were two reasons behind the errors in pragmalinguistics: lexical and message force control difficulty.

Research presented by Pishghadam et al. (2011) investigates Iranian EFL learners' persuasive strategies. Their study aimed to examine how persuasive strategies are applied. The instrument used in this study was a discourse completion test. The findings indicated that there were differences and similarities between male and female Iranian EFL learners. Query preparatory, as an indirect strategy presented in the interrogative or interrogative cum conditional form, was the strategy that was most dominant. The current study follows the method used by Pishghadam et al. (2011) in their study.

Greek EFL learners' persuasive strategies have also been investigated. This was done by Papadopoulos and Ypsilandis (2017). The aim of this research was to identify the persuasive strategies produced by EFL learners in written discourse. Sixty Greek EFL learners participated in this study. They were asked to write an informal letter to their British friends to persuade them to read a certain book. The results of the study revealed that language level has an effect on the persuasive strategies used and is not related to gender. 
One of the latest studies on the speech act of persuasion is a study by de Aquino Carlsson (2018). In this study, the persuasive strategies used by social media fitness influencers were investigated. These fitness influencers were two American females, one Spanish male, and one American male. The age of these influencers ranged from 29 to 43 years. The data collected were from Instagram posts. The researcher examined 200 posts, of which 638 speech acts were coded. The results revealed that influencers use directive sentences. This was shown in how they asked their followers to do something. The researcher stated that the limitation of the study was that it only investigated 200 posts, which may not have been sufficient to extract meaningful results.

Another recent study on persuasion is conducted by Aziz and Othman (2020). The title of the research study was "Speech Acts Uses in Persuasion and Deception in Marketing Discourse." The aim of this study was to examine the speech acts of persuasion and deception in the context of marketing discourse. The researchers' data collection method involved collecting promotional posts; there were 25 posts from 2019 to 2020 from Twitter and Facebook, which were about supplements and nutritional products. The followers and likes on these posts ranged from 160,000 to $2,000,000$. Another type of data used in this research involved videos posted on YouTube. The data were gathered from 25 videos, all of which also related to vitamins and nutritional supplements. Most of these videos were posted from 2015 to 2020. The results of the study revealed that marketers used assertive speech acts to persuade others and to avoid commitments. These commissive speech acts were used because they do not guarantee or promise the follower anything. Even though these acts may sound promising, they can be denied. The researchers concluded that the results showed the importance of studies concerning speech acts, as they can be used in marketing discourse in order to deceive the addressee.

Persuasion was also examined in the literature in different ways. Osman and Januin (2021) examined persuasion in essay writing. The aim of this research was to examine the linguistic and rhetorical structures that ESL writers from a public university in East Malaysia use in conducting a persuasive essay. The data were gathered from 15 essays written by ESL learners. The data were analysed using Toulmin's model of argument (1969) to identify linguistic and rhetorical structures. The findings revealed that all essays complied with Toulmin's model. The rebuttal stage was the only stage in which the findings were not upheld.

From the aforementioned discussion, it is clear that scarce research exists on the speech act of persuasion by Arabic EFL learners, specifically in the Saudi context. This is why the current research study will add to the body of literature on Saudi EFL persuasive strategies and gender differences in using these strategies. It will be of help to linguists and researchers to understand the persuasive strategies used by EFL learners. Awareness of these strategies, scope for improvement, and the importance of pragmatic competence will benefit language teachers and EFL learners.

\section{Research objectives:}

The objectives of this research are: 
1- To determine whether there are significant differences in how Saudi EFL learners apply their persuasive strategies.

2- To determine whether there are any significant differences between male and female Saudi EFL learners in how persuasive strategies are applied.

\section{Research questions:}

This research study aims to answer the following questions:

Q1. Are there significant differences in how Saudi EFL learners apply persuasive strategies?

Q2. Are there any significant differences between male and female Saudi EFL learners in how persuasive strategies are applied?

\section{Methods}

\subsection{Participants}

The participants of this study are 50 male and 50 female Saudi EFL learners majoring in English at two universities in Riyadh, Saudi Arabia (an all-male university and an all-female university, respectively). The participants, aged 20 to 25 years, are at level 7, which is considered the last year of the B.A. degree. Both universities offer similar courses. It is important to note that English is considered a foreign language in Saudi Arabia. Approval for the study and participation guidelines are received from the Princess Noura bint Abdulrahman University Institutional Review Board. Participants' consent is obtained before the Discourse Completion Test (DCT) is initiated. This is presented on the cover page. Participants are also notified that participation is anonymous and voluntary.

\subsection{Instrument}

The instrument used in this study is a DCT consisting of six persuasive scenarios (see Appendix). The students are expected to read each scenario and answer without overthinking their answers. The DCT is an instrument that was first introduced by Blum-Kulka and Olshtain (1984) in their cross-cultural study of speech act realization patterns. It is chosen for data collection in this study because it allows comparison between cultures in the data gathered by Morkus (2009). Morkus also adds that it is useful to manage, allowing us to gather as much data as possible, and different variables of contests are controlled, unlike naturally collected data (2009). The instrument employed in this study is created by Pishghadam et al.'s (2011) study on persuasion strategies, with slight changes made to accommodate to Saudi culture. In scenarios 1-4, the participant addresses a person of the same gender due to the Saudi culture and gender-divided schools and universities. The questionnaire contains different scenarios, namely persuasive situations, with various forms of status relationships. The addressee of the situation is either of a status considered higher, equal, or lower than that of the addressor. Instructions on how to answer the DCT are provided on the cover page. A pilot study is conducted on 13 male and 12 female students at levels 6 and 7 to ensure that the DCT is comprehended. Validity of the DCT is also assured by sharing the questionnaire with colleagues to get their responses, and comments as well as feedback are received. The results confirm the 
clarity and efficiency of the DCT. The reliability of the research is achieved using the questionnaire tested by the pilot study sample size participants. The results of the pre-tests are consistent, and the DCT is also thoroughly checked to ensure it is unbiased and free of errors.

\subsection{Procedure}

The female participants are given direct and written instructions by the researcher. A male adult is trained to explain the research and collect data from the male participants. This is because of the educational system in Saudi Arabia, where male and female students are separated. Written instructions are also provided. Participants are instructed not to hesitate to ask for clarifications, if they need any. The time frame is 20 minutes for all groups. The analysis of the data is done using Cross-Cultural Speech Act Realization Project (CCSARP) scale, which has been used by numerous linguistic researchers. It is also used by Pishghadam et al. (2011) in their study. As pointed out by Pishghadam et al. (2011), this scale consists of three categories: internal modification, external modification, and level of directness. The persuasive strategies used are examined from the perspective of directness. This perspective has a nine-point scale: hedge performatives, performatives, mood derivables, obligation statements, query preparatory, strong hints, want statements, suggestory formula, and mild hints. This nine-point scale is divided into three areas: direct, non-conventionally indirect, and conventionally indirect. The direct level consists of mood derivable, performatives, hedge performatives, obligation statement, and want statements. Mood derivable is a strategy that employs imperatives as its main form of utterances; for example, "Bring the book." Performatives are utterances where illocutionary acts are clearly stated; for example, "I now pronounce you husband and wife." Hedge performatives are an illocutionary force where utterances are softened by using expressions of hedging; for example, "We would like to ask you to lower your voice." Obligation statements are when illocutionary acts contain utterances in which the hearer is being asked by the speaker to perform an act; for example, "You should bring the book tomorrow." The "want statements" are the speaker's needs, wants, wishes, and desires or acts that the speaker would like the hearer to perform; for example, "I really wish you would pass the exam." The conventional indirect level consists of a "suggestory formula" and a "query preparatory." The "suggestory formula" refers to the utterances that suggest an act to be performed by the hearer; for example, "How about listening to some music?" The "query preparatory" refers to the use of interrogatives, and is also referred to as a preparatory condition; for example, "Would you mind giving me a pen?" The last area is the "non-conventionally indirect level," which consists of "strong hints" and "mild hints." "Strong hints" refers to "utterances that make partial reference to the act or may indicate reason or support for the desired act" (Pishghadam et al. 2011:4). For example, "It is hot here." "Mild hints" refers to utterances inferred by context; for example, "Are you available?"

Quantitative data analysis is done according to Pishghadam et al.'s (2011) method, using the nine-point CCSARP scale. The unit of scale used is the sequence 
of utterances or the head act of utterance. The Statistical Package for the Social Sciences program is used for the frequency analysis of responses. A chi-square test is used for data analysis in the last step.

\section{Results}

The aim of this study is to investigate Saudi EFL learners' persuasive strategies by comparing and contrasting strategies among females and males. The coding scheme CCSARP is used to analyse the responses. The tables below show the analysed data.

As Table 1 demonstrates, all strategy types are employed by Saudi EFL learners, although different frequencies are revealed. The results are summarized in Table 2.

Table 1. Frequency and Percentage of Persuasion Formulas used by Saudi EFL

Learners

\begin{tabular}{|l|l|l|}
\hline Strategy & Frequency & Percentage \\
\hline Mood derivable & 19 & $3.17 \%$ \\
\hline Performatives & 150 & $25.00 \%$ \\
\hline Hedge performatives & 181 & $30.17 \%$ \\
\hline Obligation statements & 13 & $2.17 \%$ \\
\hline Want statements & 44 & $7.33 \%$ \\
\hline Suggest & 148 & $24.67 \%$ \\
\hline Query & 13 & $2.17 \%$ \\
\hline Strong hints & 2 & $0.33 \%$ \\
\hline Mild hints & 30 & $5.00 \%$ \\
\hline Total & 600 & $100.00 \%$ \\
\hline
\end{tabular}

Table 2. The Results of the Chi-square for the Strategies Selected by EFL Students

\begin{tabular}{|l|l|l|l|l|l|l|}
\hline Strategy & $\begin{array}{l}\text { Observed } \\
\text { N }\end{array}$ & $\begin{array}{l}\text { Expected } \\
\text { N }\end{array}$ & $\begin{array}{l}\text { Residu } \\
\text { al }\end{array}$ & $\begin{array}{l}\text { d } \\
\text { f }\end{array}$ & $\begin{array}{l}\text { Chi- } \\
\text { square }\end{array}$ & Sig \\
\hline Mood derivable & 19 & 66.67 & -47.67 & - & - & - \\
\hline Performatives & 150 & 66.67 & 83.33 & - & - & - \\
\hline
\end{tabular}




\begin{tabular}{|l|l|l|l|l|l|l|}
\hline $\begin{array}{l}\text { Hedge } \\
\text { performatives }\end{array}$ & 181 & 66.67 & 114.33 & - & - & - \\
\hline $\begin{array}{l}\text { Obligation } \\
\text { statements }\end{array}$ & 13 & 66.67 & -53.67 & - & - & - \\
\hline Want statements & 44 & 66.67 & -22.67 & - & - & - \\
\hline Suggest & 148 & 66.67 & 81.33 & - & - & - \\
\hline Query & 7 & 66.67 & -59.67 & - & - & - \\
\hline Strong hints & 8 & 66.67 & -58.67 & - & - & - \\
\hline Mild hints & 30 & 66.67 & -36.67 & - & - & - \\
\hline Total & 600 & - & - & 8 & 609.660 & 0.00 \\
& & & & & & 0 \\
\hline
\end{tabular}

As Table 2 shows, the most dominant strategy types used by Saudi EFL learners are hedge performatives, performatives, and suggest strategies. As seen, the hedge performatives strategy's frequency (observed $\mathrm{N}=181$, expected $\mathrm{N}=66.67$ ) is much higher than expected. With respect to the performatives strategy, the frequency (observed $\mathrm{N}=150$, expected $\mathrm{N}=66.67$ ) is also higher than expected, as is that of the suggest strategy (observed $\mathrm{N}=148$, expected $\mathrm{N}=66.67$ ). Moreover, the results indicate that the least preferred strategy types used by Saudi EFL learners are query, strong hints, obligation statements, and mood derivable strategies. As can be seen in Table 2, the query strategy (observed $\mathrm{N}=7$, expected $\mathrm{N}=66.67$ ), strong hints strategy (observed $\mathrm{N}=8$, expected $\mathrm{N}=66.67$ ), obligation statements (observed $\mathrm{N}=13$, expected $\mathrm{N}=66.67$ ), and mood derivable (observed $\mathrm{N}=19$, expected $\mathrm{N}=66.67$ ) have significantly lower frequencies than expected.

To discover whether there are significant differences between the performance of male and female Saudi EFL learners in persuasion strategies, a chisquare test is carried out. The results of the comparison of the Chi-square test for the strategies selected by male and female Saudi EFL learners are presented in Table 3.

Table 3. Results of the Chi-square for Strategies Selected by EFL Students based on Gender

\begin{tabular}{|l|l|l|l|l|l|l|l|}
\hline \multirow{2}{*}{ Strategy } & \multicolumn{2}{|l|}{ Observed N } & \multicolumn{2}{l|}{ Expected N } & \multirow{2}{*}{ Df } & $\begin{array}{l}\text { Chi- } \\
\text { Square }\end{array}$ & Sig \\
\cline { 2 - 7 } & Male & Female & Male & Female & \\
\hline
\end{tabular}




\begin{tabular}{|l|l|l|l|l|l|l|l|}
\hline Mood derivable & 12 & 7 & 9.5 & 9.5 & 1 & 1.316 & 0.251 \\
\hline Performatives & 78 & 72 & 75.0 & 75.0 & 1 & .240 & 0.624 \\
\hline $\begin{array}{l}\text { Hedge } \\
\text { performatives }\end{array}$ & 93 & 88 & 90.5 & 90.5 & 1 & .138 & .710 \\
\hline $\begin{array}{l}\text { Obligation } \\
\text { statements }\end{array}$ & 9 & 4 & 6.5 & 6.5 & 1 & 1.923 & .166 \\
\hline Want statements & 12 & 32 & 22.0 & 22.0 & 1 & 9.091 & .003 \\
\hline Suggest & 72 & 76 & 74.0 & 74.0 & 1 & .108 & .742 \\
\hline Query & 2 & 5 & 3.5 & 3.5 & 1 & 1.286 & .257 \\
\hline Strong hints & 7 & 1 & 4.0 & 4.0 & 1 & 4.500 & .034 \\
\hline Mild hints & 15 & 15 & 15.0 & 15.0 & 1 & .000 & 1.000 \\
\hline
\end{tabular}

As Table 3 demonstrates, there are significant differences between males and females in their preference for the strategy of want statements (Chi-square $=9.091$, $\mathrm{p}<.05$ ), which are mostly selected by females, and the strategy of strong hints (Chisquare $=4.500, \mathrm{p}<.05$ ), which are mostly selected by males.

\section{Discussion}

The aim of this study is to explore differences in Saudi EFL learners' use of persuasive strategies and to investigate gender differences in the application of persuasive strategies. The results of the study demonstrate that hedge performative and performative strategies are the top two highest-ranking strategies preferred by Saudi EFL learners. These two strategies are direct strategies. This is consistent with Hardin's (2010) study which reveals that non-native speakers tend to use speech act verbs that are explicit. However, this is not consistent with other study results (Blum-Kulka et al. 1984; Hong 1999; Tatton 2008), which find that language speakers and cultures generally tend to use indirect strategies when performing a speech act. It is also not consistent with Pishghadam et al.'s (2011) findings that non-native speakers apply more indirect strategies.

The third top highest-ranking strategy used by participants is a conventional indirect strategy, namely the suggestory formulae strategy. The fact that it is one of the top three high-ranking strategies applied shows similarities with Pishghadam et al.'s (2011) study. This also confirms the findings of Blum-Kulka et al. (1984), Hong (1999), and Tatton (2008).

As for the differences in persuasion strategies applied between male and female Saudi EFL learners, the results reveal that there are significant differences 
between the genders in their choice of applying direct strategies, namely, mood derivable, performatives, hedge performatives, obligation statements, and want statements. The direct strategies are mostly applied by males. This finding is consistent with that of Lackoff (1975) regarding how men talk compared with women. In her study, she argues that women's speech is less direct than men's speech. However, this finding does not show any similarity with the findings of Lamude (1993) concerning how males tend to use soft strategies with other men when attempting to influence them. The significant differences in the results demonstrate that the indirect strategy of strong hints is used more by males, and the want statements strategy is mostly used by females. Moreover, the Saudi culture and gender separation in the education system, given that the participants are university students, as well as the fact that scenarios 1-4 are based on an educational context, may have impacted the results.

The results also show that female participants use more conventional indirect strategies compared to males. This is also shown in the findings related to the narrative formula strategy and the query preparatory strategy. This finding is consistent with Pishghadam et al.'s (2011) findings. It also aligns with the theory of social constructionism, which implies that both genders' style of language changes based on the social context (Coates and Johnson, 2001; Leaper and Smith, 2004). However, this finding contradicts that of Smith (2009), in which there are no significant differences between genders.

With regard to Saudi male EFL learners, they prefer to apply the strong hints strategy in persuasive scenarios, which is a non-conventional indirect strategy. This again proves Lamude's (1993) findings and contradicts those of Lackoff(1975). As with the mild hints strategy, the results show no differences between genders, which aligns with the findings of other researchers such as Al-Khateeb (2009).

\section{Conclusion}

In conclusion, Saudi EFL learners tend to use more direct strategies in English, namely performatives and hedge performatives which confirms Hardin's (2010) statement that EFL learners tend to use direct speech acts strategies. As regards gender differences, male Saudi EFL learners tend to use more direct strategies than female Saudi EFL learners and this proves Lackoff's (1975) assertion that males are more direct than females. The findings of this study are of great importance to foreign language teachers, researchers, and students, emphasizing the need to consider the cultural context that may affect the choice of employing direct or indirect strategies. It is also of great importance for language teachers to introduce these findings to students as it will help them in their journey of foreign language learning. I will also help them in knowing which aspects of speech acts strategies they need to focus on when teaching. This research would be useful for future studies to conduct a cross-cultural analysis of the directness level of the speech act of persuasion between Saudi EFL learners and native English speakers. Other aspects - such as social distance and power - that might affect the persuasive strategy used should also be considered in future research. It would also be 
interesting to investigate other EFL learners in different native languages and cultures and their pragmatic competence.

The limitations of the study are that it only investigates Saudi EFL learners and does not include native speakers, which would have provided more information relating to different linguistic aspects. This limitation is due to the difficulty in finding native English-speaking Saudi participants. Moreover, a larger sample of participants would have provided verity and more detailed information. Other data collection methods could be used to explore the possibilities of other persuasive strategies by EFL learners (such as real-life recordings and role-playing).

Acknowledgment: This research was funded by the Deanship of Scientific Research at Princess Nourah bint Abdulrahman University through the Fast-track Research Funding Program.

Rehan Almegren

Department of Applied Linguistics, College of Languages

Princess Nourah bint Abdulrahman University, Riyadh, Saudi Arabia

ORCID Number: 0000-0003-0931-6434

Email: rmalmagran@pnu.edu.sa

\section{References}

Alhudhaif, Abdulrahman M. (2005). A speech act approach to persuasion in American and Arabic editorials. Unpublished PhD Dissertation, Purdue University, West Lafayette, USA.

Al-Khateeb, Sana M. (2009). The speech act of thanking as a compliment response as used by the Arab speakers of English: A comparative intercultural study. Unpublished Master Thesis, An-Najah National University, Nablus, Palestine.

Austin, John. L. (1962). How to do things with words. Oxford: Oxford University Press.

Aziz, Sara A. H. and Shamal K. Othman. (2020). 'Speech acts uses in persuasion and deception in marketing discourse'. Journal of University of Babylon for Humanities, 28 (6): 62-73.

Blum-Kulka, Shoshana and Elite Olshtain. (1984). 'Requests and apologies: A cross-cultural study of speech act realization patterns (CCSARP)'. Applied Linguistics, 5: 196-213. 
Brown P. and Levinson, S. (1987) Politeness: Some universals in language usage. Cambridge: Cambridge University Press.

Bryant Smith, J. (2009). The acquisition of pragmatic competence: Complement response strategies in learners of Spanish. An unpublished doctoral dissertation, Louisiana State University, USA.

Chakorn, Ora-Ong. (2006). 'Persuasive and politeness strategies in cross-cultural letters of request in the Thai business context'. Journal of Asian Pacific Communication, 16 (1): 103-146.

Coates, Linda and Trudy Johnson. (2001). 'Towards a social theory of gender'. In Howard Giles and W. P. Robinson (Eds.), The new handbook of language and social psychology, 451-464. Chichester, UK: Wiley.

de Aquino Carlsson, Alissa. (2018). Persuasion in social media: A study of Instagram influencers usage of persuasive speech acts. Unpublished Thesis. Linnaeus University. http://urn.kb.se/resolve?urn=urn:nbn:se:Inu:diva-69900 (Retrieved on 29 March, 2021)

Færch, Claus and Gabriele Kasper (eds.). (1983). Strategies in interlanguage communication. London: Longman.

Gass, Susan and Noel Houck. (1999). Interlanguage refusals: A cross-cultural study of Japanese English. Berlin: Mouton de Gruyter.

Hardin, Karol. J. F. (1999). Pragmatics in persuasive discourse of Spanish television advertising. Unpublished Dissertation, University of Texas, Austin.

Hardin, Karol. (2010). 'Trying to persuade: Speech acts in the persuasive discourse of intermediate Spanish learners'. In Kenneth, A., McElhanon, and Ger Reesink (Eds.), A mosaic of languages and cultures, 155-179. Cambridge: Cambridge University Press.

Hong, Gao. (1999). 'Features of request strategies in Chinese'. Lund University Working papers, 47: 73-86.

Jibreen, Maysa and Hiba Hameed Hamzah Al-Janabi. (2018). 'The relationship between persuasion and speech act theory'. Journal of Al-qadisiya in Arts and Educational Sciences, 18 (3): 29-37.

Kasper, Gabriele. (1992). 'Pragmatic transfer'. Second Language Research, 8 (3): 203-231.

Kasper, Gabriele and Kenneth R. Rose. (2002). Pragmatic development in a second language. Oxford: Blackwell.

Koike, Dale April. (1996). 'Transfer of pragmatic competence and suggestions in Spanish foreign language learning'. In Susan M. Gass and Joyce Neu (Eds.), Speech acts across cultures: Challenges to communication in a second language, 257-281. Berlin: Mouton de Gruyter.

Lakoff, Robin. (1975). Language and women's place. New York: Harper \& Row.

Lakoff, Robin. (1982). 'Persuasive discourse and ordinary conversation, with examples from advertising'. In Deborah Tannen (Ed.), 
Analyzing discourse: Text and talk, 239-311. Washington DC: Georgetown University Press.

Lamude, Kevin G. (1993). 'Supervisors' upward influence tactics in same-sex and cross-sex dyads'. Perceptual and Motor Skills, 77: 1067-1070.

Leaper, Campbell and Tara E. Smith. (2004). 'A meta-analytic review of gender variations in children's language use: Talkativeness, affiliative speech, and assertive speech'. Developmental Psychology, 40: 993-1027.

Morkus, Nader. (2009). The realisation of the speech act of refusal in Egyptian Arabic by American learners of Arabic as a foreign language. Unpublished Doctoral Dissertation, University of South Florida.

Osman, Wan \& Junaidah Januin. (2021). 'Analysing ESL persuasive essay writing using Toulmin's Model of argument'. Journal of Education \& Psychology, 58: 1810-1821.

Papadopoulos, Isaak and George Ypsilandis. (2017). 'Towards an understanding of the persuasive profile of teenaged Greek EFL learners'. Journal of Applied Languages and Linguistics, 1 (1): 61-75

Pishghadam, Reza and Parisa Rasouli. (2011). 'Persuasive strategies among Iranian EFL learners'. Studies in Literature and Language, 3 (2): 111-117.

Searle, John. R. (1976). 'A classification of illocutionary acts'. Language in Society, 5(1), 1-23.

Searle, John. R. (1969). Speech acts: An essay in the philosophy of language. Cambridge: Cambridge University Press.

Selinker, Larry. (1972). 'Interlanguage'. International Review of Applied Linguistics in Language Teaching, 10: 209-241.

Taguchi, Naoko. (2009). 'Pragmatic competence in Japanese as a second language: An introduction'. In N. Taguchi (Ed.), Pragmatic competence, 1-18. Berlin: Mouton de Gruyter.

Tatton, Heather. (2008). “'Could you, perhaps, pretty please?” Request directness in cross-cultural speech act realization'. Studies in Applied Linguistics \& TESOL, 8 (2): 1-4.

Taufik, Kani Sulam. (2014). 'The Persuasive utterances in a political discourse'. International Journal of Linguistics, 6 (1): 192-208.

Toulmin, S. (1969). The uses of argument. Cambridge University Press: Cambridge.

Verschueren, Jef. (1999). Understanding pragmatics. Oxford: University Press.

Yule, George. (1996). Pragmatics. Oxford: University Press.

\section{Appendix}

Dear participants,

Thank you for your time in answering this questionnaire. I would like to inform you that your participation is voluntary, your answers will be anonymous, and will only be used for the purpose of this research. 


\section{'By completing this questionnaire, I agree to my answers being used for the purpose of this research'.}

1. Age:

2. Native language:

3. Department of study at university: Level:

4. Number of years studying English:

\section{Instructions:}

1- $\quad$ Read each situation carefully.

2- $\quad$ Respond to each situation naturally without overthinking it.

\section{Completing this questionnaire is appreciated and will help in the success of this study.}

1-You really have to take a course in order to graduate, but you found out that the course is already closed. So, you decide to persuade the person in charge, who you don't know, to allow you to take the course. What would you say to persuade her to permit you to participate in the course?

I would say:

2-You have a paper due in one of your classes next week. However, you will be very busy this week and don't have any time to write it. You go to your professor's office to persuade her to give you more time to write the paper. What would you say?

I would say:

3- You were absent from last Tuesday's English class. So, you decide to borrow your friend's notes to catch up with the rest of the class. What would you say to persuade her/him to lend you the notes?

I

would

say:

4- It's 7:00 a.m. and you want to go to work. You have to leave your daughter alone because her babysitter is late. You decide to persuade your friend, who lives in the neighbourhood, to take care of your little daughter in the meantime. What would you say? 


\section{I would say:}

5- You have a bill that needs to be paid urgently. Although you have the money, you do not have the time to make the payment. You know that your little brother has free time and knows how to do it. You decide to persuade him to pay the bill on your behalf. What would you say?

I would say:

6- You are the owner of a big bookstore. It is the beginning of the semester and you are very busy. Today, you want to extend business hours by an hour so you decide to persuade your clerk, who you know quite well, to stay for an extra hour. What would you say?

\section{I would say:}

Thank you 